\title{
Book Note
}

\section{Behavior Analysis Language Instrument and Behavior Analysis Language Program: A Short Review}

\author{
Louise Kent-Udolf \\ Region II Education Service Center \\ Corpus Christi, Texas
}

The $B A L I$ is an assessment instrument and the $B A L P$ is a companion piece that presents the theory and rationale behind the $B A L I$ and the author's training methods. According to the authors, the $B A L I$ is designed for people of all ages with severe and profound handicaps. The intended audience includes all who serve this population. As the authors state, it is quite possible to use the $B A L I$ without consulting any other material, including the $B A L P$. These materials are based on the Skinnerian analysis of verbal behavior.

The $B A L I$ is divided into four language skill areas: receptive (mand compliance), expressive labeling (tacting), requesting (manding), and beginning conversational (intraverbal). The authors suggest that the user select several objectives in each skill area to assess. For each skill area, a long list of objectives is provided along with appropriate forms that allow for the assessment of each objective with ten trials for each vocabulary item, up to 10 items. The user decides which objectives and which vocabulary items to assess.

The $B A L P$ is a manual or tutorial comprised of four sections. The first section presents the author's view of a behavior analysis perspective of language. This

Cipani, E., Johnston, D., Burger, S., Torres, L., Rowe, T., \& Reynolds, H. (1988). Behavior Analysis Language Instrument (BALI): Assessment of beginning language in people with profound and severe handicaps. Bellevue, WA: Edmark Corporation (184 pages) and Cipani, E. (1988). Behavior Analysis Language Program (BALP): Theory, assessment and training practices for personnel working with people with severe handicaps. Bellevue, WA: Edmark Corporation (49 pages). view is simply stated to the point of omitting any mention of the role of the audience or the possibility of multiple stimulus control. The author clearly makes the point, however, that communication or language can and does occur in a variety of modes other than speech - for example, gestures, manual signs, written text, and outputs of various augmentative/alternative communication devices or systems such as communication boards and electronic speech output computers.

The second section defines and gives examples of the five types of verbal behavior addressed: duplic, tact, mand, intraverbal, and receptive. This section is clear. It is almost too simplistic. Again, there is no discussion of the audience or of multiple stimulus control. Implied is that a complete description of verbal operants can be achieved through the specification of one controlling stimulus, the response, and a reinforcing consequence mediated by a person.

The third section expands on the behavioral assessment procedures. Here are six very useful pages covering topics ranging from how to establish rapport with persons with severe handicaps to how to maintain performance during testing by interspersing easy or already acquired items. I have two problems with this section. One is the use of the term "non-discriminative stimulus." What is it? My other problem is the author's lack of regard for the value of family input in the assessment process.

The fourth section presents a limited technology for beginning language acquisition. There is a short discussion of incidental teaching formats and their im- 
portance to the teaching of language in natural contexts. The rest of this section is devoted to discussion and examples of the "Quick Transfer" procedure as it applies to the types of verbal repertoires addressed.

The rationale for the $B A L I$ is consistent with current trends in services for persons with the most severe handicapping conditions. Practitioners generally have concluded that developmental models are not appropriate either for assessment or for teaching communication and language to this population. The pervasiveness of communication and language skill deficits among persons in this population and the importance of such skills for maximal participation in functional environments are widely recognized. There is a need for assessment and instruction that promote acquisition of functionally relevant communication and language skills in natural contexts and that facilitate social interaction. With the exception of the short discussion of incidental teaching formats in the $B A L P$, the $B A L I$ and the $B A L P$ fall short of meeting this need. For example, how functional is it for a person to be able to recite on request lists of colors, lists of TV shows, lists of animals, lists of animals that live in water, and so on? To be fair, the authors have included personal I.D. objectives that could be very functional under appropriate circumstances. Although there is a hint that the authors favor concurrent instruction (simultaneous instruction on the same objectives in school and non-school environments), this notion is not developed.

There is overwhelming emphasis on a training approach that pays little heed to the importance of providing opportu- nities for social interaction or the natural contexts in which behaviors, if mastered, might be expected to occur. Instruction in natural contexts is highly valued in current educational practice and is thought to be importantly related to generalization and maintenance (Horner, Dunlap, \& Koegel, 1988). Social interaction is also highly prized and is thought to add longitudinal value to instruction as well as to offer opportunities favorable to generalization and maintenance.

Lastly, two categories of verbal behavior not addressed and important for social acceptance are greetings such as " $\mathrm{hi"}$ and the exchange of polite verbal rituals such as "please," "thank you," "excuse me," and "I'm sorry."

In summary, the $B A L I$ and $B A L P$ are interesting to behavior analysts because they describe an assessment and training process for verbal behavior that is based on Skinnerian analysis. The procedures are clearly described and useful as far as they go. Although the authors provide a rationale for these materials that is consistent with current trends in practice among professionals serving persons with the most severe handicaps, the objectives advanced for assessment and training do not give sufficient consideration to functionality, natural contexts, opportunities for social interaction, and social significance. Practitioners who use the $B A L I$ and the $B A L P$ should supplement them with additional technology to address this deficiency.

\section{REFERENCE}

Horner, R. H., Dunlap, G., \& Koegel, R. L. (1988). Generalization and maintenance: Life-style changes in applied settings. Baltimore, MD: Paul H. Brookes. 